EDITORIAL

The British Association of Sport and Medicine, jointly with the British Olympic Association, held a one-day symposium on Altitude Training, at the Royal Society of Medicine, London, last November. The idea of giving an athlete training under the stress of diminished oxygen tension to adapt his body to greater endurance for events at sea level would appear to be reasonable on purely physiological grounds, and training under these conditions has been attempted by athletes in several countries. Remarkable successes have also been made by athletes whose normal habitat is at altitude, and they have dominated endurance running events for the past six years or so. There are few data available on the physiological effects of short exposure to altitude stresses, and the two organisations therefore attempted to collect scientific facts from acknowledged authorities who were then asked to present this information at the symposium.

Apart from the physiological aspects, other considerations also play an important part in deciding whether or not altitude training be engaged in. Taking a team away from the normal environment of its members and giving them intensive training may have a most beneficial effect upon many, whether this training is at altitude or not. If it were to last for more than two weeks, there could be restlessness and poor morale amongst some, marital upsets, insecurity of continued employment for the amateur athlete, and other psychological disturbances that can occur when any group of people are living in strange or unfamiliar surroundings. There is also the important question of finance; a residential training camp in one's own country is an expensive enough matter, but to find a suitable environment to bring about any measurable physiological change, the team must be taken and maintained abroad, with the logistical problems this involves. Subjective impressions from athletes, coaches and doctors participating in altitude training have been collected, and discussed. Scientific evidence has been obtained and the results presented. One thing that could not be done was to give categorical answers to:

1. Is altitude training the only sure way of improving the performance of the endurance runner?

2. Is altitude training of such limited value that it is not justified on the grounds of cost, morale and time?

3. For how long a period should one train at altitude?

\section{How often?}

5. When should altitude training cease prior to an event?

This issue of the British Journal of Sports Medicine is devoted to the Proceedings of this Symposium on Altitude Training. Professor Keul, who has had considerable experience in the medical care of the West German teams, including their altitude training, brings first-hand scientific information. We were disappointed that Professor E. R. Buskirk was prevented from crossing the Atlantic at the last moment, but we were most fortunate in having the invaluable services of Professor Roy Shephard, who flew over from Canada, arriving in the middle of the morning of the symposium, and returning as soon as he had given his help in the panel discussion, and before he could be informed that at the Annual General Meeting of the British Association of Sport and Medicine that followed, he was elected unaminously an Honorary Life Member of the Association. The Chair was taken most ably, at the morning session and at the panel discussion by a clinician with experience in exercise physiology, Dr. Roger Bannister, and at the afternoon session by a distinguished physiologist, Dr. B. B. Lloyd.

Due acknowledgement has been made to both the British Olympic Association and to Abbott Laboratories Ltd., for generous financial help. We are also most indebted to the latter for arranging for the tapes of the meeting to be transcribed, and for Dr. Robert Richardson to undertake the editing of these Proceedings, which entailed. also extensive labour in transcribing discussions recorded on tape, and the inclusion of material given by the main speakers that was not in their rough notes from which the verbal communications were given.

With the industrial situation improving a bit, we hope to get this issue and the next out soon, before the inevitable rise in costs makes us reduce our publications or increase our subscriptions.

H. E. Robson 